\title{
Pescadores de Manoel Urbano e a construção de um território de pesca numa perspectiva etnoecológica*
}

\section{Fishermen in Manoel Urbano and the framing of a fishing territory from an ethnoecological perspective}

\author{
Antonio Francisco Perrone Oviedo ${ }^{1}$
}

Artigo recebido em: 17 de novembro de 2017 Artigo aprovado em: 30 de novembro de 2017

\begin{abstract}
Resumo: Dentro de uma perspectiva etnoecológica, este trabalho foi realizado junto com os pescadores artesanais do município de Manoel Urbano, Acre. Para tanto, terá por foco a pesca nos rios e lagos do município, atividade de importância fundamental para estas comunidades. Os pescadores possuem uma percepção própria da hidrodinâmica dos ambientes e do comportamento dos estoques de peixes, e com isso definem suas regras de manejo. Os procedimentos metodológicos envolveram a observação participante, entrevistas e questionários aplicados a pescadores experientes. Os resultados evidenciam um registro histórico das práticas e concepções relativas às formas de socialização com este território de pesca.
\end{abstract}

Palavras-chave: Pesca artesanal, conhecimento local, Amazônia.

\begin{abstract}
From an ethnoecological perspective, this work was carried out together with the communities of artisanal fishermen of the municipality of Manoel Urbano, State of Acre. In order to do so, it will focus on fisheries management in rivers and lakes of the municipality, an activity of fundamental importance to these communities. Fishermen have their own perception of hydrodynamics of their environments and the behavior of fish stocks, and thus define their management rules. The methodological procedures involved participant observation, interviews, and questionnaires applied to experienced fishermen. The results evidenced a historical record of the practices and conceptions related to the forms of socialization with this fishing territory.
\end{abstract}

Key Words: Artisanal fishing, local knowledge, Amazon.

*Este estudo contou com financiamentos da Gordon and Bettty Moore Foundation (Amazon Headwaters Initiative - Sub-Outcome 1.5, fases I e II); Secretaria de Secretaria Extensão Agroflorestal e Produção Familiar do Estado do Acre - SEAPROF (Projeto Alto Purus); Secretaria Especial de Aquicultura e Pesca SEAP/PR (Projeto extensão pesqueira: manejo de lagos nos municípios Manuel Urbano e Sena Madureira, estado do Acre, No. 00350.004175/2005-39).

${ }^{1}$ Pós-doutorado em Políticas Públicas e Gestão Ambiental pelo Centro de Desenvolvimento Sustentável (CDS) da Universidade de Brasília UnB). Doutor pelo CDS/UnB e Mestre em Geografia pela Universidade de São Paulo. Graduado em Ciências Agrárias pela Universidade de Taubaté, com especialização em drenagem e manejo de bacias hidrográficas pela Universidade de Taubaté, Geselschaft for Technische Zuzammenarbeit (GTZ) e Institute of Land Reclamation and Improvement (ILRI). E-mail: antoniopoviedo@gmail.com 


\section{Introdução}

A etnoecologia surge em contraponto ao modelo das políticas pesqueiras baseadas em métodos de avaliação de estoques (DIEGUES 1999; PRINCE 2009) e tem se mostrado uma abordagem valiosa para o estudo das interações do homem com o ambiente (AGRAWAL 1999; MARQUES, 2001). Além disso, tem fornecido caminhos na investigação científica e construção de sistemas de manejo de recursos pesqueiros (CASTELLO, 2004). As comunidades tradicionais de pescadores são detentoras de um rico conjunto de conhecimentos e práticas de uso dos recursos pesqueiros e ecossistemas associados. Diversos autores têm estudado como estas comunidades interagem com tais recursos (CASTRO e MCGRATH 2003; MOURÃO e NORDI 2003; SILVANO 2004; SILVANO e BEGOSSI, 2005), bem como influenciam os debates e políticas públicas que envolvem o uso sustentável dos recursos pesqueiros (AYRES 1994; MCGRATH et al., 2008). A coparticipação entre cientistas, gestores públicos e cidadãos pode gerar estratégias relevantes para o uso e conservação dos recursos naturais, especialmente em regiões de conflito pelo acesso e uso destes recursos (ROZZI et al. 2006; MCGRATH et al., 2015; OVIEDO \& BURSZTYN, 2016).

Os sistemas de manejo adaptativo são caracterizados por um complexo conhecimento etnoecológico que é transmitido oralmente entre as gerações, bem como sofre uma complementação significativa por meio do engajamento dos indivíduos nos fenômenos do ambiente, e habilidades que são adquiridas na prática (INGOLD, 2010). É na paisagem dos rios e lagos, constituída pelos traços impressos por aqueles que pescaram anteriormente e que pescam no momento, que o conhecimento etnoecológico pode ser acessado. Além de envolver um grande número de espécies e informações sobre 0 meio ambiente, este conhecimento pode fornecer um importante subsídio para a construção de sistemas de manejo que sejam compatíveis com a realidade dos pescadores (SILVANO, 2004; CASTELLO et al. 2011; INGOLD, 2011).

A chave para se compreender a efetividade destes sistemas de manejo está em tomar como foco a atividade em si mesma, que resulta em um conjunto de características e feedbacks que são incorporados na paisagem. Os resultados e dissonâncias decorrentes das práticas diárias de manejo da pesca são recursos valiosos usados pelos pescadores para adaptar a configuração e composição espacial dos seus sistemas de uso 
da terra e dos recursos naturais (VOGT et al., 2016). Estudos sobre as interações entre caçadores e recursos naturais têm dado grande importância ao papel das relações entre "organismos-ambientes", demonstrando que nessas relações ocorrem processos semeIhantes e simétricos entre as diferentes formas de vida e o ambiente (APPADURAI, 1986; INGOLD, 2000; 2011). Decorre daí a possibilidade da etnoecologia, como uma ciência interdisciplinar, de revisar as fronteiras entre as ciências sociais e as ciências naturais, entre os processos biológicos e político-institucionais, ao mesmo tempo que aproxima os diferentes campos do conhecimento científico e local. Neste sentido, objetivou-se a construção do campo cognitivo e das habilidades dos pescadores de Manoel Urbano, cujo território de pesca representa uma importante região da Amazônia (SANTOS FILHO, 2005; ALBERT e REIS 2011). Pretende-se verificar se o conhecimento local dos pescadores representou uma base significativa de informações para a construção do sistema de manejo comunitário em curso (BERKES, 2008).

\section{Material e métodos}

As comunidades estudadas localizam-se no município de Manoel Urbano, Acre (Figura 1). Ao longo rio Purus e seus lagos adjacentes que se delimita o território comunitário pesqueiro. O trabalho de campo deste estudo teve início em 2003 e término em 2010. Três técnicas são utilizadas para coleta de dados, a observação participante, as entrevistas e a aplicação de um questionário sobre a captura e esforço de pesca.

A técnica de observação participante (SCHWARTZ e SCHWARTZ 1955) foi aplicada com o apoio de um diário de campo (VIERTLER, 2002), por meio da participação em viagens de pesca, reuniões de pescadores, reuniões entre pescadores e agências governamentais, confraternizações, cursos de extensão rural, conversas informais do cotidiano e preparativos para a pescaria. Esta técnica objetivou à convivência com os aspectos ecológicos do rio Purus, o processo dos pescadores de aquisição do conhecimento, e as suas interações com o ambiente e outros atores sociais. A observação participante foi associada à dois tipos de entrevistas, informal ou etnográfica e semiestruturada (Bernard e Ryan, 2010), as quais geraram informações sobre as práticas individuais e coletivas de pesca. A entrevista informal se inicia com base em duas perguntas: Na sua experiência, como você decide por uma pescaria? Quando outros pescadores 


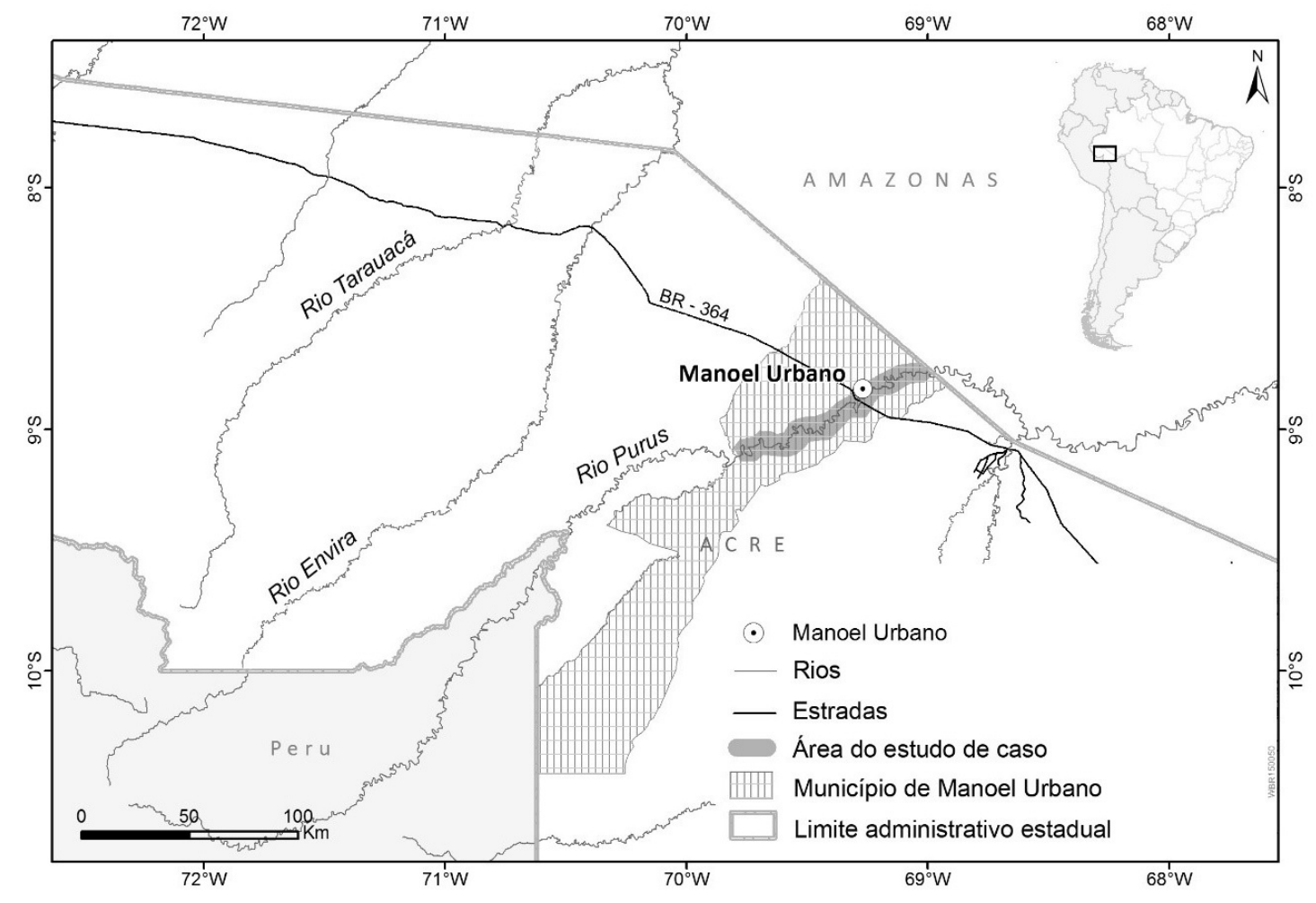

Figura 1. Município de Manoel Urbano, estado do Acre.

estão realizando práticas ilegais, que atitude você pode tomar? No total, foram realizadas 60 entrevistas etnográficas. A entrevista semiestruturada considerou um conjunto de perguntas: Quais são os locais de pesca próximos da sua comunidade? Qual a situação da pesca na sua comunidade? As regras de pesca estão sendo discutidas? As comunidades estão decidindo sobre as regras de pesca? Os órgãos do governo atuam nas regras de pesca? Quem está implementando as regras de pesca? Os benefícios alcançam a comunidade? No total, foram realizadas 153 entrevistas semiestruturadas. Os entrevistados foram apontados pelos próprios membros da comunidade ou selecionados durante as atividades de campo.

Uma narrativa padrão foi adotada para a descrição das práticas e eventos sobre a pesca de modo a facilitar a transcrição das entrevistas e a identificação de temas ou padrões. Utilizou-se técnicas de corte e classificação (LINCOLN \& GUBA, 1985) para organizar expressões em pilhas de respostas que se juntam como tema. O software de análise de dados qualitativos MaxQDA (VERBI, 2017) foi usado para codificar as entrevistas transcritas. A análise dos temas emergentes permitiu a identificação de expres- 
sões de significação de regras sociais (GEERTZ, 1989) na interação dos pescadores com o ambiente de pesca e, a partir daí, foram codificadas, visando um diálogo do conhecimento local com a regulamentação da pesca. Ainda, foi realizada uma revisão das políticas e normas de pesca relevantes para identificar o marco legal da pesca no rio Purus.

O questionário da estatística pesqueira, proposto por Ruffino (2008: 196), foi aplicado a um grupo de 176 pescadores, os quais reportaram os dados sobre a captura e esforço de pesca (identidade do pescador, tipo de embarcação, local de pesca, espécies capturadas, arreios de pesca, produção pesqueira e custos), durante o período de 2003 a 2010. A aplicação dos questionários foi coordenada por quatro funcionários da Secretaria Extensão Agroflorestal e Produção Familiar do Estado do Acre (SEAPROF), que gerencia um sistema de informações dos produtores rurais. A análise das capturas por unidade de esforço (CPUE) foram feitas com base no volume de captura e número de malhadeiras ( $\mathrm{kg}$ malhadeira ${ }^{-1}$ ). Os dados obtidos em pares de lagos similares, que posteriormente são submetidos à diferentes níveis de manejo (com e sem manejo), foram analisados utilizando o pacote estatístico BioEstat (AYRES et al. 2007). Foi realizada a análise de variância (ANOVA) de critério único, e a diferença entre as médias foi analisada pelo teste Tukey para a variável CPUE mensal (agrupada nos períodos de seca e cheia), sempre que o teste $\mathrm{F}$ da ANOVA foi significativo ao nível de $5 \%$ de probabilidade.

\section{Resultados}

A pesca nas comunidades ribeirinhas de Manoel Urbano é predominantemente de subsistência, com a comercialização do pescado excedente. Existem ainda, pescadores urbanos (residentes na cidade de Manoel Urbano), que além da pesca de subsistência, comercializam o excedente. A produção pesqueira é orientada para o consumo local, uma vez que o município oferece infraestrutura precária para armazenagem do pescado. O município possui duas instituições locais responsáveis pela gestão dos recursos pesqueiros, a Colônia de Pescadores Z-5 e a Associação de Pescadores de Pirarucu de Manoel Urbano, as quais atuam na implementação de regras de pesca nos 13 lagos do município, além da calha principal do rio Purus. Existem 32 comunidades nas áreas adjacentes ao rio Purus (190 famílias, 853 habitantes), as quais não têm associações 
comunitárias de moradores. Não existe uma estrutura formal de liderança ou de representação das comunidades junto às instituições locais. As comunidades constituem-se basicamente de uma estrutura remanescente dos seringais, baseada em núcleos familiares, com baixa densidade demográfica e pouca articulação político-institucional. Poucos moradores são filiados à Colônia de Pescadores. Durante o período deste estudo, os pescadores relataram as limitações da Colônia, especialmente em infraestrutura, recursos humanos, participação no ordenamento pesqueiro e repasse de informações corretas aos pescadores. A Colônia realiza reuniões e/ou assembleias para debater as atividades, mas a participação dos pescadores é baixa (em torno de $30 \%$ dos associados).

A frota pesqueira de Manoel Urbano é composta de canoa motor de rabeta (61\%), canoa (18\%), barco pescador (16\%) e barco misto (5\%). Os principais arreios de pesca utilizados são as malhadeiras (89\%), com comprimento médio de $60 \mathrm{~m}$ e malha entre 60-70 mm e 100-110 mm, e as tarrafas (11\%), com malha acima de $50 \mathrm{~mm}$. Os desembarques pesqueiros anuais dos pescadores envolvidos neste estudo totalizaram, em média, 17,5 toneladas. O pico da produção ocorre entre os meses de julho a setembro, com a pesca nos lagos e a piracema de pequenos bagres como mandi, branquinha e curimatá. A pesca nos lagos responde por $86 \%$ do pescado capturado (os outros $14 \%$ são pescados no rio Purus). Os lagos Bela Vista, Novo, Santarém e Santo Antonio são os mais visitados, correspondendo a $24,6 \%, 18 \%, 12,3 \%$ e $8,3 \%$, respectivamente, do volume total de pesca do município.

Tabela 1: Espécies utilizadas e conhecimento local sobre o hábito trófico segundo os pescadores de Manoel Urbano.

\begin{tabular}{l|l|l}
\hline Nome comum & Nome científico & Hábito trófico \\
\hline Acari-bodo & Liposarcus pardalis & $\begin{array}{l}\text { "Limo"orgânico, microorganismos e resíduos } \\
\text { associados ao fundo de lagos e rios }\end{array}$ \\
\hline Barba-chata & Pinirampus pirinampu & Peixes \\
\hline Bico-de-pato & Sorubim cf. lima & $\begin{array}{l}\text { Pequenos peixes, camarões, insetos e ara- } \\
\text { nhas }\end{array}$ \\
\hline
\end{tabular}

Esta tabela continua na próxima página. 


\section{Continuação da Tabela 1}

\begin{tabular}{|c|c|c|}
\hline Nome comum & Nome científico & Hábito trófico \\
\hline Bodó & Hipostomus sp. & Insetos, algas e resíduos orgânicos \\
\hline Bodó-piteiro & Loricariichthys sp. & Insetos, algas e resíduos orgânicos \\
\hline Bodó-cascudo & Hipostomus sp. & Insetos, algas e resíduos orgânicos \\
\hline Branquinha & Potamorhina latior & $\begin{array}{l}\text { Matéria orgânica vegetal (frutos, folhas, flo- } \\
\text { res e raízes) e microorganismos que se acu- } \\
\text { mulam no fundo dos lagos e remansos de } \\
\text { igarapés }\end{array}$ \\
\hline $\begin{array}{l}\text { Branquinha } \\
\text { cabeça-lisa }\end{array}$ & $\begin{array}{l}\text { Potamorhina altamazo- } \\
\text { nica }\end{array}$ & Matéria orgânica vegetal e microorganismos \\
\hline $\begin{array}{l}\text { Branquinha cas- } \\
\text { cuda }\end{array}$ & Psectrogaster amazonica & Matéria orgânica vegetal e microorganismos \\
\hline Cachorra & Cynodon gibus & Peixes \\
\hline Caparari & $\begin{array}{l}\text { Pseudoplatystoma tigri- } \\
\text { num }\end{array}$ & Pequenos peixes \\
\hline Cará & Geophagus brasiliensis & $\begin{array}{l}\text { Pequenos peixes, insetos, larvas e matéria } \\
\text { orgânica vegetal (folhas, frutos) no fundo dos } \\
\text { lagos e remansos de igarapés }\end{array}$ \\
\hline Charuto/Saúna & Hemiodus sp. & $\begin{array}{l}\text { Algas, macrófitas aquáticas, matéria orgâ- } \\
\text { nica vegetal (fragmentos, sementes, flores, } \\
\text { frutos), insetos (aranhas e ácaros) }\end{array}$ \\
\hline Cuiu-cuiu & Pionopsitta pileata & $\begin{array}{l}\text { Larvas de insetos e aranhas, camarões, que } \\
\text { vivem no fundo de rios e lagos }\end{array}$ \\
\hline Curimatá & Prochilodus nigricans & $\begin{array}{l}\text { Algas, insetos (libélula e mosca-de-água), } \\
\text { caracóis, matéria orgânica vegetal e microor- } \\
\text { ganismos associados ao "limo"orgânico em } \\
\text { lagos e rios }\end{array}$ \\
\hline Dourada & $\begin{array}{l}\text { Brachyplatystoma flavi- } \\
\text { cans }\end{array}$ & Peixes \\
\hline Filhote & $\begin{array}{l}\text { Brachyplatystoma fila- } \\
\text { mentosum }\end{array}$ & Peixes \\
\hline
\end{tabular}

Esta tabela continua na próxima página. 
Continuação da Tabela 1

\begin{tabular}{|c|c|c|}
\hline Nome comum & Nome científico & Hábito trófico \\
\hline Jandiá & Leiarius marmoratus & $\begin{array}{l}\text { Pequeno peixes, insetos e material orgânico } \\
\text { vegetal. }\end{array}$ \\
\hline Jaú & Paulicea luetkeni & Peixes \\
\hline Mandi & Pimelodus blochii & $\begin{array}{l}\text { Insetos, material orgânica vegetal e peque- } \\
\text { nos peixes }\end{array}$ \\
\hline Mapará & Hypophthalmus sp. & Algas, pequenos crustáceos \\
\hline Matrinchã & Brycon cephalus & $\begin{array}{l}\text { Frutos e sementes (seringa, abio, açaí, } \\
\text { araçá, jauari, bacaba), matéria orgânica ve- } \\
\text { getal (folhas, caules), insetos (mosca-de- } \\
\text { água, libélulas, besouros, mosquitos), ara- } \\
\text { nhas }\end{array}$ \\
\hline Pacu & Mylossoma duriventre & $\begin{array}{l}\text { Pequenos peixes, insetos, sementes (jeni- } \\
\text { papo, seringa, andiroba, ingá, embaúba) e } \\
\text { materia orgânica vegetal (frutos, folhas, flo- } \\
\text { res e raízes) }\end{array}$ \\
\hline Piramutaba & $\begin{array}{l}\text { Brachyplatystoma vail- } \\
\text { lanti }\end{array}$ & Peixes \\
\hline Peixe-cachorra & Rhaphiodon vulpinus & Peixes e sementes \\
\hline Peixe-cachorra & Hidrolycus scomberoides & Peixes e sementes \\
\hline Peixe-gato & Platydoras costatus & Caracóis, camarões e resíduos orgânicos \\
\hline Pescada & Plagioscion sp. & $\begin{array}{l}\text { Pequenos peixes, camarões, insetos (mosca- } \\
\text { de-água, libélulas, besouros, mosquitos), } \\
\text { matéria orgânica vegetal (folhas, frutos e se- } \\
\text { mentes) }\end{array}$ \\
\hline Piau-listrado & Schizodon sp. & $\begin{array}{l}\text { Algas e matéria orgânica vegetal (folhas, fru- } \\
\text { tos e sementes) }\end{array}$ \\
\hline Piau-pintado & Leporinus sp. & $\begin{array}{l}\text { Algas e matéria orgânica vegetal (folhas, fru- } \\
\text { tos e sementes), caracóis, peixes menores }\end{array}$ \\
\hline Piracatinga & Calophysus macropterus & Peixes \\
\hline
\end{tabular}

Esta tabela continua na próxima página. 


\section{Continuação da Tabela 1}

\begin{tabular}{l|l|l}
\hline Nome comum & Nome científico & Hábito trófico \\
\hline Pirarucu & Arapaima gigas & $\begin{array}{l}\text { Peixes, sementes, insetos (mosca-de-água, } \\
\text { libélulas, besouros, mosquitos, cigarrinhas) e } \\
\text { camarão }\end{array}$ \\
\hline Piranha & Serrasalmus sp. & Peixes \\
\hline Piranha-branca & Serrasalmus elongatus & Peixes \\
\hline Piranha-cajú & Pygocentrus nattereri & Peixes \\
\hline Tambaqui & Colossoma macropomum & $\begin{array}{l}\text { Pequenos frutos e sementes (abio, açaí, cas- } \\
\text { tanheira, jenipapo, jauari, fava, seringa, an- } \\
\text { diroba, ingá, embaúba), matéria orgânica ve- } \\
\text { getal (folhas, caules) }\end{array}$ \\
\hline Traíra & Hoplias malabaricus & Peixes \\
\hline Sabarú & Curimatella sp. & Insetos, sementes, matéria orgânica vegetal \\
\hline Sardinha & Triportheus trifurcatus & $\begin{array}{l}\text { Matéria orgânica vegetal (frutos, sementes), } \\
\text { insetos (mosca-de-água, libélulas, besouros, } \\
\text { mosquitos) e aranhas }\end{array}$ \\
\hline Sica-do-ó & Roeboides sp. & Matéria orgânica vegetal, insetos e aranhas \\
\hline Sardinha-branca & Triportheus elongatus & Matéria orgânica vegetal, insetos e aranhas \\
\hline Tamoatá & Holplosternum litoralle & $\begin{array}{l}\text { Insetos (mosquitos, mosca-de-água), resí- } \\
\text { duos orgânicos e caracóis }\end{array}$ \\
\hline & Peixes, insetos (besouros) e sementes \\
\hline
\end{tabular}

Os pescadores artesanais de Manoel Urbano se distribuem nas comunidades ribeirinhas, em geral compostas de até dez residências. Há também casas isoladas nas margens dos rios. As casas são feitas de madeira, itaúba (Mezilaurus itauba) e cedro (Cedrela fissilis), com cobertura de palha ou telha. Algumas casas são construídas sobre palafitas, para evitar o alagamento no período de cheia do rio. Em suas casas, possuem TV $(63 \%)$, rádio $(27 \%)$, fogão (100\%), forno de farinha $(59 \%)$, e filtro de água (31\%). Os pescadores entrevistados possuem, em média, 36 anos de idade e 18 anos de experiência, com grau de instrução médio (até a $4^{a}$ série). Noventa por cento dos pescadores são casados e possuem, em média, 3 filhos. A maior parte das famílias se fixou a partir da extração de borracha, residindo no interior da floresta, ou no "centro", como denominado regionalmente. 
Os pescadores desenvolvem uma economia de subsistência bastante diversificada. Foram citadas 62 espécies de plantas cultivadas, entre frutas, grãos, hortaliças e legumes, sendo as mais importantes a mandioca, milho, banana, cana, arroz, feijão, cupuaçu, laranja, limão, abacate, graviola, melancia, jerimum, mamão e abacaxi. Dos produtos que retiram da mata, 21 espécies são utilizadas, entre frutas, palhas e sementes, com destaque para o açaí (Euterpe oleracea), bacuri (Platonia insignis), castanha (Bertholletia excelsa), patauá (Oenocarpus bataua), cacau (Theobroma cacao), jací (Orbignya phalerata), seringa (Hevea brasiliensis L.), buriti (Mauritia flexuosa) e bacaba (Oenocarpus bacaba). Além de 60 espécies de plantas utilizadas para fins medicinais, tais como malvarisco (Plectranthus amboinicus), alfavaca (Ocimum americanum), mastruz (Chenopodium ambrosioides), copaíba (Copaifera landesdorffi), boldo (Plectranthus barbatus), jatobá (Hymenaea courbaril), hortelã (Mentha spicata), agrião (Spilanthes oleracea), pariri (Arrabidaea Chica), catinga de mulata (Tanacetum vulgare), maracujá (Passiflora edulis), cumaru (Dipteryx odorata), macela (Achyrocline satureioides), bordão de velho (Samanea saman), pau d'arco roxo (Tabebuia impetiginosa), capim santo (Cymbopogon citratus), e bálsamo (Sedum dendroideum). Os roçados possuem uma área média de 1,75 ha e a criação de animais envolve o gado bovino (30\% são criadores, com rebanhos em média de 8 cabeças), além de porcos, patos e galinhas.

Os pescadores entrevistados demonstraram um rico conhecimento sobre os ambientes de pesca (i.e. rios, igarapés, sangradouros, lagos, furos, igapós, capim e floresta) e as espécies de peixes. As práticas de pesca refletem a dinâmica do rio, já que as escolhas dessas atividades estão relacionadas aos movimentos de enchente (novembro a fevereiro), cheia (março a junho), vazante (julho), e seca (agosto a outubro). A pesca é uma atividade desenvolvida durante o ano todo, mas mostra um caráter mais intenso no período da vazante e da seca, quando os lagos se encontram mais piscosos. Nesse período, os pescadores utilizam 4,6 dias semana ${ }^{-1}$ para pescar, preferencialmente nos lagos, com duração média de 11,3 horas $\mathrm{dia}^{-1}$ e captura por viagem em torno de $103 \mathrm{~kg}$. No inverno, todos os pescadores pescam em média 2,6 dias semana ${ }^{-1}$, com duração média de 12 horas dia $^{-1}$ e captura por viagem de 29,6 kg; o que resulta em uma CPUE média de $2,0 \mathrm{~kg} \mathrm{~h}^{-1}$ no período de seca e $0,9 \mathrm{~kg} \mathrm{~h}^{-1}$ no período de cheia.

Os pescadores relataram um profundo conhecimento sobre os 13 lagos do mu- 
nicípio (Bela Vista, Novo, Santarém, Santo Antonio, Bananal, Grande, Cumarú, Novo Destino, Aracajú, Oriente, Terra Nova, Pau Seco e São Pedro). As descrições detalhadas envolvem um conjunto de conhecimentos sobre o histórico de formação (e dinâmica) dos lagos, dimensões, profundidades, estimativa de área, intensidade de capim e macrófitas aquáticas, restrições de acesso sazonal e tamanho das embarcações, uso da terra no entorno, condições do sangradouro e principais espécies de peixes que habitam anualmente o lago. $O$ consumo de pescado envolve um total de 43 espécies de peixes (Tabela 1), destacando-se o mandi, filhote, curimatá, branquinha, acari-bodó, mapará, pescada, piau, jandiá, traíra, cascudo, sardinha, saúna e piramutaba. O conhecimento dos pescadores sobre o hábito trófico dos peixes também é apresentado na Tabela 1. Ainda, informações sobre o que os peixes não comem, variações na dieta e local de alimentação são relatadas pelos pescadores.

Durante as entrevistas e anotações realizadas nas reuniões e eventos sobre a pesca, foi possível identificar os principais conflitos existentes: pesca de arrastão em círculo com malhadeiras emendadas $(29,8 \%)$, uso de malhadeira em áreas impróprias (i.e. fechando rios, igarapés e lagos) (12,8\%), falta de conhecimento sobre a legislação de pesca $(12,8 \%)$, uso do tingui nos lagos e igarapés $(10,6 \%)$, pesca de arrojo nos igarapés $(8,5 \%)$, presença frequente de pescadores comerciais nos lagos $(6,4 \%)$, pesca de batição de tarrafa em área cercada com malhadeiras $(6,4 \%)$, pesca com malha inferior à permitida pela legislação ambiental $(6,4 \%)$, descarte de peixe na beira do lago $(4,3 \%)$ e pesca na época de desova (2\%). Uma espécie indicada pelos pescadores como ameaçada é o mandi, onde os desembarques mensais ocorrem nos meses de setembro e outubro. Os pescadores relatam uma diminuição dos estoques de mandi em decorrência da sobrepesca realizada nos municípios à jusante do rio Purus (Sena Madureira e Boca do Acre), refletindo a falta de regulamentação específica para a espécie. Sobre o controle da pesca ilegal, $86 \%$ dos entrevistados relataram preocupação a respeito da ausência dos órgãos de fiscalização e como esta situação prejudica a garantia do acesso ao recurso pesqueiro.

Em 2003, o governo estadual do Acre (SEAPROF) iniciou um trabalho em conjunto com as comunidades visando a construção de acordos coletivos de pesca como mecanismo para a resolução de conflitos e ordenamento da pesca. O I Fórum Municipal 
de Pesca de Manoel Urbano, realizado no mês de março de 2004, marcou o início de um debate sobre a percepção local da pesca e como este conhecimento poderia apoiar 0 ordenamento pesqueiro. Estavam presentes 20 delegados representantes das comunidades, delegados da Colônia de Pescadores Z-5, 36 pescadores artesanais, e representantes das seguintes organizações: SEAPROF, Sindicato dos Trabalhadores Rurais, IBAMA, Associação Agroextrativista dos Trabalhadores Rurais de Manoel Urbano, Instituto de Meio Ambiente do Acre (IMAC), Secretária Estadual de Ação Social, INCRA, SEBRAE, Instituto de Defesa Agropecuária e Florestal do Acre, Secretaria Municipal de Agricultura, Secretaria Municipal de Educação, Câmara Municipal, Colônia de Pescadores Z-3 de Sena Madureira. O evento promoveu um espaço para a gestão participativa, onde novas regras de pesca foram projetadas a partir do conhecimento local. As propostas de acordos de pesca foram validadas e encaminhadas ao IBAMA e IMAC para posterior regulamentação.

A realização do fórum promoveu um intenso processo de compartilhamento de conhecimentos sobre a pesca, e envolveu diversas etapas: reuniões intercomunitárias para diagnóstico da pesca, reuniões preparatórias para o fórum, debates e aprovação das propostas durante o fórum, reuniões pós-fórum para negociar impasses e aprimorar as regras, formatação de um processo administrativo a ser encaminhado ao IBAMA e IMAC, recebimento e debates do parecer do IBAMA e IMAC, publicação e divulgação do acordo de pesca nas comunidades. Os primeiros acordos de pesca foram regulamentados no segundo semestre de 2005, nos lagos Bela Vista e Novo (Instrução Normativa IBAMA no 18/06/2005) e Santo Antonio (Instrução Normativa IBAMA no 57/11/2005). O acordo para os lagos Bela Vista e Novo estabeleceu limites na quantidade de malhadeiras e tarrafas (5 malhadeiras pescador ${ }^{-1}$ no Bela Vista, e 1 malhadeira e 1 tarrafa pescador $^{-1}$ no Novo), limite no volume de captura por embarcação (100 kg pescaria ${ }^{-1}$ ) e proibição da pesca no período noturno. O acordo do lago Santo Antonio estabeleceu regras específicas para o manejo do pirarucu (proibição da pesca do pirarucu e do o uso de malhadeira pelo período de um ano), proibição da pesca de subsistência no período noturno, proibição do uso de tarrafa com malha inferior a seis centímetros, número máximo de 4 canoas de uso coletivo no lago, e limite na pesca de subsistência ( $3 \mathrm{~kg}$ mais um exemplar). Ambos os acordos também regulamentam as disposições sobre penalidades, 
conforme a Lei no 9.605/1998 e o Decreto no 3.179/1999.

Dentre os pescadores entrevistados, $84 \%$ conheciam quais eram as principais regras estabelecidas pelos acordos de pesca. Uma quantidade menor de entrevistados (58\%) soube responder detalhes dos acordos (i.e. quantidade de malhadeiras e volumes de captura). A maioria dos entrevistados (69\%) nas comunidades com acordos de pesca afirmou que o instrumento foi bem-sucedido na resolução dos conflitos. Sobre a porcentagem de moradores da comunidade que cumprem as regras do acordo, $53 \%$ afirmaram que mais de $50 \%$ dos moradores estão pescando em conformidade com as regras. Ainda, $62 \%$ dos pescadores locais sentem-se intimidados em tomar alguma atitude diante da ocorrência de práticas ilegais.

Em 2008, as comunidades, instituições locais e agências governamentais promoveram o II Fórum Municipal de Pesca de Manoel Urbano, que avaliou a implementação dos acordos regulamentados em 2005 e revisou algumas regras. As novas regras ampliaram o uso da malhadeira e tarrafa nos lagos Bela Vista e Novo em 20\% e 60\%, respectivamente (Instrução Normativa IBAMA no 199/11/2008), bem como estabeleceu limites na pesca comercial $\left(60 \mathrm{~kg}\right.$ em até duas pescarias no Bela Vista e $35 \mathrm{~kg}$ pescaria ${ }^{-1}$ no Novo) e de subsistência (10 kg pescaria ${ }^{-1}$ ). Para o manejo do pirarucu, o acordo de pesca (Instrução Normativa IBAMA no 198/11/2008) ampliou o número de lagos (Santo Antonio, Santarém e Grande), permitindo o manejo conforme autorização da superintendência do IBAMA - Acre. Ainda, o acordo limitou horários de pesca, quantidade permitida na pesca de subsistência (5 $\mathrm{kg}_{\text {pescaria }}{ }^{-1}$ ), quantidade de tarrafa (01) por pescador, e número máximo de 6 e 4 canoas de uso coletivo no Santo Antonio e Grande, respectivamente. Um ponto de atenção relatado pelos pescadores é que não fica definido nos acordos de pesca como o acompanhamento das regras deve ocorrer, bem como quais as instituições envolvidas na vigilância e fiscalização.

As entrevistas realizadas após a revisão dos acordos, em 2009, relataram que $34 \%$ conheciam quais eram as novas regras estabelecidas. A maioria dos entrevistados (90\%) nas comunidades com acordos de pesca afirmou que produção pesqueira tem se mantido estável. Porém, $73 \%$ dos entrevistados relataram problemas com o manejo do pirarucu (i.e. pesca ilegal, falta de prestação de contas, redução no apoio institucional da 
SEAPROF). Existem expectativas dos pescadores de melhoria da produção pesqueira no médio e longo prazo, considerando experiências na Amazônia que comprovam que regiões manejadas oferecem maior produtividade (ALMEIDA et al. 2009). A Tabela 2 apresenta os dados do esforço de pesca (CPUE), durante o período de 2003 a 2010, em 6 lagos do município que somam $71 \%$ dos registros de pesca.

O impacto dos acordos de pesca sobre os lagos manejados, quando comparado aos lagos sem manejo, foi avaliado em termos de CPUE $\left(\mathrm{kg}\right.$ malhadeira $\left.{ }^{-1}\right)$ conforme a Tabela 3. O resultado mostrou que não há diferença significativa no esforço de pesca entre as pescarias com e sem acordos de pesca, exceto para o Lago Santo Antonio. Neste caso, a produtividade foi significativamente maior no lago manejado (Santo Antonio) quando comparada com um lago similar sem regras de manejo. Na média, a CPUE foi $82,9 \%$ mais alta no lago manejado (Tabela 3 ). 
Tabela 2: Dados do esforço de pesca (CPUE) em 06 lagos do

município de Manoel Urbano (2003 a 2010)

\begin{tabular}{|c|c|c|c|c|c|c|c|c|c|c|c|c|c|c|c|}
\hline \multicolumn{16}{|c|}{ CPUE (kg malhadeira ${ }^{-1}$ ) } \\
\hline & \multirow[t]{2}{*}{2003} & $2003-$ & 2004 & 2004- & 2005 & $2005-$ & 2006 & $2006-$ & 2007 & $2007-$ & 2008 & $2008-$ & 2009 & $2009-$ & 2010 \\
\hline & & \multicolumn{2}{|l|}{2004} & \multicolumn{2}{|l|}{2005} & \multicolumn{2}{|l|}{2006} & \multicolumn{2}{|l|}{2007} & \multicolumn{2}{|l|}{2008} & \multicolumn{2}{|l|}{2009} & \multicolumn{2}{|l|}{2010} \\
\hline & seca & cheia & seca & cheia & seca & cheia & seca & cheia & seca & cheia & seca & cheia & seca & cheia & seca \\
\hline Lago Bana- & 4 & 5,34 & 9,06 & 7,43 & 9,07 & 10,17 & 8,5 & 9,26 & 9,27 & 9,37 & 7,25 & 8,34 & 7,58 & 6,63 & 7,45 \\
\hline \multicolumn{16}{|l|}{ nal } \\
\hline Lago Bela & 10,87 & 9,86 & 13,41 & 14,84 & 8,87 & 14,31 & 12,14 & 12,09 & 12,42 & 12,76 & 11,65 & 11,17 & 18,42 & 12,53 & 14,49 \\
\hline \multicolumn{16}{|l|}{ Vista } \\
\hline Lago Santo & 12,61 & 11,87 & 8,42 & 10,47 & 23,16 & 11,11 & 12,98 & 20,1 & 22,22 & 18,62 & 19,88 & 12,48 & 14,64 & 12,92 & 14,78 \\
\hline \multicolumn{16}{|l|}{ Antonio } \\
\hline Lago Santa- & 23,12 & 19,18 & 15,2 & 13,23 & 14,82 & 13,04 & 8,07 & 11,44 & 15,32 & 15,44 & 10,16 & 12,03 & 9,27 & 13,71 & 10,85 \\
\hline \multicolumn{16}{|l|}{ rém } \\
\hline Lago Novo & 9,51 & 7,49 & 14,61 & 9,06 & 13,04 & 8,18 & 7,9 & 8,49 & 6,85 & 10,58 & 7,94 & 7,11 & 11,33 & 8,59 & 8,58 \\
\hline Lago & 5,81 & 11,74 & 10,53 & 9,87 & 12,68 & 10,3 & 9,42 & 9,44 & 10,41 & 11,71 & 9,23 & 10,32 & 7,39 & 11,37 & 6,87 \\
\hline Grande & & & & & & & & & & & & & & & \\
\hline
\end{tabular}


Tabela 3: Espécies utilizadas e conhecimento local sobre o hábito trófico segundo os pescadores de Manoel Urbano.

\begin{tabular}{|c|c|c|c|c|}
\hline \multirow{2}{*}{ Lagos - Fatores } & \multicolumn{4}{|l|}{$\begin{array}{l}\text { Antes do Acordo de } \\
\text { Pesca }(2003-2005)\end{array}$} \\
\hline & $\begin{array}{l}\text { CPUE - Seca } \\
\text { e Cheia - (kg } \\
\left.\text { malhadeira }^{-1}\right)\end{array}$ & $\begin{array}{l}\text { CPUE - Seca } \\
\text { e Cheia - (kg } \\
\left.\text { malhadeira }^{-1}\right)\end{array}$ & $\begin{array}{l}\text { CPUE } \\
\text { Seca - } \quad(k g \\
\left.\text { malhadeira }^{-1}\right)\end{array}$ & $\begin{array}{l}\text { CPUE } \\
\text { Cheia - } \quad(k g \\
\left.\text { malhadeira }^{-1}\right)\end{array}$ \\
\hline Bananal - SM & $6,45 a$ & $8,44 \mathrm{a}$ & $8,18 \mathrm{a}$ & $8,75 \mathrm{a}$ \\
\hline Novo - CM & $10,16 \mathrm{a}$ & $\begin{array}{l}\text { 8,96 a } \\
\text { ANOVA Valor F }\end{array}$ & $9,27 \mathrm{a}$ & $8,59 \mathrm{a}$ \\
\hline $\begin{array}{l}\text { Manejo - acordo de } \\
\text { pesca }\end{array}$ & $3,79 \mathrm{~ns}$ & $0,61 \mathrm{~ns}$ & $1,09 \mathrm{~ns}$ & $0,03 \mathrm{~ns}$ \\
\hline CV \% & 38,34 & 17,65 & 20,67 & 14,24 \\
\hline Grande - SM & $9,48 a$ & $10,11 \mathrm{a}$ & $9,11 \mathrm{a}$ & $10,62 \mathrm{a}$ \\
\hline Santo Antonio - CM & $10,84 \mathrm{a}$ & $\begin{array}{l}\text { 16,77 b } \\
\text { ANOVA Valor F }\end{array}$ & $17,43 b$ & $15,04 \mathrm{~b}$ \\
\hline $\begin{array}{l}\text { Manejo - acordo de } \\
\text { pesca }\end{array}$ & $1,26 \mathrm{~ns}$ & 15,09 ** & 13,54 * & 5,72 * \\
\hline CV \% & 38,68 & 34,39 & 40,24 & 28,09 \\
\hline Santarém - SM & $17,68 \mathrm{a}$ & $12,54 \mathrm{a}$ & $12,09 a$ & $12,98 \mathrm{a}$ \\
\hline Bela Vista - CM & $12,24 \mathrm{a}$ & $\begin{array}{l}\text { 11,92 a } \\
\text { ANOVA Valor F }\end{array}$ & $11,89 a$ & $12,58 \mathrm{a}$ \\
\hline $\begin{array}{l}\text { Manejo - acordo de } \\
\text { pesca }\end{array}$ & $4,82 \mathrm{~ns}$ & $0,32 \mathrm{~ns}$ & $0,17 \mathrm{~ns}$ & $0,13 \mathrm{~ns}$ \\
\hline CV \% & 29,09 & 17,26 & 22,21 & 11,42 \\
\hline
\end{tabular}

Nível de significância estatística: * $p<0,01 ;{ }^{*} p<0,05$ e ns não significativo. Nível de manejo: SM (sem manejo) e CM (com manejo) nos pares de lagos com letras iguais não diferem significativamente entre si ao nível de 5 


\section{DISCUSSÃO}

Os pescadores de Manoel Urbano relataram um conjunto de conhecimentos sobre o ambiente e comportamento dos peixes, relacionados a percepção dos movimentos, sons ou sinais quando se movimentam, ou ainda hábitos de migração e defesa de predadores. Segundo Leme e Begossi (2004), o conhecimento sobre os ambientes de pesca e a distribuição dos recursos pesqueiros é de extrema importância nas interações feitas pelas populações ribeirinhas. Os pescadores também demonstraram um amplo conhecimento sobre as técnicas de captura e os arreios utilizados, relatando todos os processos com uma vasta riqueza de detalhes. Marques (2001) aponta o caráter prático desse conhecimento, onde os materiais, as técnicas e a habilidade na realização das práticas são determinantes para o sucesso da atividade. Costa-Neto et al. (2002) e Mourão e Nordi (2003) relacionam os modelos cognitivos sobre o comportamento dos peixes a etnocategorias, vinculando-as aos fenômenos etológicos observados (produção de som, migração, comportamento). Um exemplo sobre a percepção e categorias etológicas dos pescadores de Manoel Urbano é a técnica aplicada para a estimativa da população de pirarucus nos lagos do município. Trata-se da observação do comportamento do peixe em subir periodicamente (a cada 20 minutos) à superfície para respirar (ato que o pescador chama de buiada), o que permite aos pescadores detectarem visual ou auditivamente o indivíduo, realizando a contagem (incluindo estimativas de idade, sexo, tamanho e peso). Comparações entre essas estimativas e experimentos controlados mostraram a acurácia desta técnica (CASTELLO 2004), a qual vem sendo utilizada no manejo sustentável da espécie em diversas regiões da Amazônia (CASTELLO et al. 2011, OVIEDO e CROSSA, 2011; MCGRATH et al. 2015). Ruddle (1993: 20) discute a elaboração de novas práticas e estratégias de pesca desenvolvidas por pescadores com base no conhecimento local, onde se destacam alta especificidade e eficiência na captura, bem como o poder de predição. Nesse sentido, os pescadores de Manoel Urbano utilizam as estimativas da contagem visual para um processo de tomada de decisão e autorizações legais sobre as cotas anuais de pesca (OVIEDO e BURSZTYN 2016). Este caso evidencia o papel positivo do conhecimento local como subsídio para o licenciamento ambiental e planejamento das atividades (estimativa de safra e insumos, duração da pescaria, infraestrutura de armazenamento e comercialização). 
Para quem pudesse achar paradoxal, o manejo específico do pirarucu, baseado em uma abordagem ecossistêmica, adquiriu suporte empírico quando os pescadores passam a relatar um aumento da produção pesqueira de outras espécies, desde quando o pirarucu começou a ser manejado, sugerindo o impacto positivo do manejo ao longo da cadeia trófica do ecossistema. Porém, todos os pescadores são unânimes em afirmar que a fiscalização não funcionou bem, especialmente no controle das malhadeiras. A partir de 2009, os pescadores passaram a relatar invasões nos lagos manejados. Um evento marcante foi a invasão de malhadeiras no lago Santo Antonio, onde em um único dia foram apreendidas mais de 20 malhadeiras dispostas de forma ilegal. A ausência de prestação de contas pela Associação de Pescadores de Pirarucu de Manoel Urbano desencadeou novos conflitos com os comunitários e demais pescadores, os quais se sentiam prejudicados na repartição do benefício desta pescaria. Ainda em 2009, o governo estadual retira sua participação nesta iniciativa com as comunidades e inicia uma agenda de fomento à aquicultura na região. Esta ambiguidade nas políticas pesqueiras desencadeia um mercado ilegal de alevinos de pirarucu e aumenta as invasões nos lagos. Aliado à fraca fiscalização do IBAMA, os estoques de pirarucus, que mostravam sinais de recuperação (aumento de 89\% entre 2005 a 2009), foram praticamente dizimados em 2010 (Oviedo et al. 2015). Apesar de algum sucesso e do engajamento de alguns pescadores, o território de pesca de Manoel Urbano parece estar seriamente ameaçado, pois a frágil gestão participativa exercida pela Colônia de Pescadores, Associação de Pescadores de Pirarucu e as comunidades apresenta limitações para o enfrentamento dos conflitos.

De forma geral, podemos analisar esses conflitos com base no conceito de território de pesca. Santos (2006) descreve a configuração de um território como local que apresenta recursos naturais e diversos modos de uso superpostos. Os conflitos de pesca em Manoel Urbano configuram um território de pesca, uma vez que considera o ambiente natural que está sendo apropriado por um grupo social, sob formas de proteção ou de regras de uso, ou ainda sob conflitos de uso (RAFFESTIN, 1993). A iniciativa no lago Santo Antonio, onde práticas de manejo do pirarucu foram implementadas (i.e. suspensão das malhadeiras, avaliação dos estoques), redirecionado o uso do lago para a pesca de subsistência e manejo de uma espécie específica, reflete uma preocupação da 
comunidade com a conservação do recurso (o pirarucu) dentro de seu território.

A construção do território de pesca de Manoel Urbano, tendo os acordos de pesca como forma de socialização, apresenta vários aspectos importantes do ponto de vista das interações dos pescadores com o ambiente: (i) estabelece territórios comunitários formais e passa uma parcela significativa da sua gestão para os moradores e instituições locais; (ii) reconhece os usos individuais e coletivos dos ambientes, sendo compatível com o atual padrão de ocupação e uso dos recursos pesqueiros; (iii) integra o manejo do ecossistema num único instrumento de gestão, que é construído coletivamente pelos moradores e define as regras para o uso dos recursos naturais; (iv) a regulamentação do acordo de pesca como uma área protegida comunitária (KOTHARI, 2006), permite em tese a cobrança de taxas pela associação dos moradores para a entrada de pescadores de fora, criando um mecanismo para financiar as atividades de manejo realizadas pelas comunidades; (v) o respeito às regras do acordo de pesca passou a ser determinante para a manutenção do território e garantia de acesso e uso do recurso pesqueiro.

Uma das regras chaves do acordo de pesca para o controle do esforço é a limitação ou proibição de malhadeiras. Durante o período de seca, as malhadeiras são usadas, em média, por $89 \%$ dos pescadores. Isso implica em um custo elevado para a fiscalização dos acordos de pesca. Contudo, o fato das regras do acordo estabelecerem limites baseados na percepção dos pescadores, e permitirem que os moradores das comunidades pesquem a mesma quantidade que eles pescavam sem o acordo, pode explicar a ausência de uma alteração significativa no esforço de pesca nos lagos manejados. Ainda, o acordo de pesca como um instrumento pactuado entre os pescadores pode funcionar como um fator que contribui para a estabilidade no esforço de pesca dos lagos do município ao longo dos anos, evitando flutuações mais intensas (Tabela 2).

Embora os dados sobre esforço e captura não forneçam as informações necessárias para avaliar o status da exploração da pesca, análises comparativas fornecem uma indicação sobre esse aspecto. O total capturado pelos pescadores artesanais em Manoel Urbano resultou em aproximadamente 17,5 $\mathrm{t}^{\mathrm{ano}}{ }^{-1}$ em uma área de pesca de 228,8 ha. Neste caso, a captura atual por área é de aproximadamente $76,5 \mathrm{~kg}$ ha ano ${ }^{-1}$. Esse dado corresponde à aproximadamente $84 \%$ da produção máxima estimada para 
um lago de pesca multiespecífica ( $91 \mathrm{~kg}$ ha $a o^{-1}$ ) na Amazônia em um estudo empírico (LORENZEN et al., 2006). Com base nesta referência, a pesca nos lagos de Manoel Urbano parece estar sendo explorada intensamente no momento presente (WELCOMME, 1999).

\section{Conclusão}

O estudo etnoecológico do manejo da pesca em Manoel Urbano propiciou vislumbrar as formas de ocupação e uso do território, bem como as diversas práticas e regras que se desenvolveram em torno da atividade pesqueira. $O$ conjunto de conhecimentos sobre os ambientes de pesca, recursos pesqueiros e as formas de ocupação das comunidades orientaram, para os pescadores, as decisões sobre os locais e regras de pesca no decorrer do tempo, e deram início a uma série de iniciativas de cogestão entre os pescadores e as agências governamentais. As habilidades e modos como os pescadores manejam a pesca, e também suas relações com o ambiente, enfatizam a dimensão dos acordos e o papel da prática para a aquisição do conhecimento. O acordo de pesca, como resultado do engajamento e aprendizagem dos pescadores na configuração do território, busca refletir a tentativa de uma simetria entre o ambiente e o modo de vida dos pescadores.

O manejo da pesca foi um fator de articulação política em torno dos direitos territoriais e da manutenção dos modos de produção das comunidades tradicionais. Para a geração de conhecimento e construção de um território de pesca, os pescadores de Manoel Urbano optaram pelo uso coletivo dos recursos pesqueiros. Escolheram compartilhar parte dos conhecimentos que compõem o manejo da pesca, especialmente os saberes relacionados às condições dos estoques, áreas prioritárias e épocas adequadas para as práticas, com o objetivo de garantir, do ponto de vista individual e comunitário, o direito de acesso e uso sustentável dos recursos pesqueiros. Entretanto, existem desafios relacionados à vigilância comunitária e fiscalização. A ausência de procedimentos claros e transparentes para a resolução de conflitos ainda dificulta a correta interpretação dos direitos dos pescadores e não tem contribuído para o aprimoramento da gestão pesqueira.

A abordagem etnoecológica adotada neste estudo demonstrou que as dimensões 
do conhecimento evidenciadas pelas categorias dos ambientes de pesca, práticas de manejo e registro das condições ecológicas dos recursos pesqueiros, somente podem continuar a existir enquanto os pescadores estiverem em interação com os ambientes e os atores sociais. Os modos de conhecer dos pescadores de Manoel Urbano estão inscritos nos ambientes e nos recursos naturais. Os acordos de pesca regulamentados e 0 processo participativo de realização dos fóruns municipais de pesca revelam um modelo para a cogestão de um território de pesca. É importante que a agências governamentais assegurarem a estas comunidades tradicionais seus direitos sobre os recursos pesqueiros e se comprometam com parcerias de longo prazo para o enfrentamento dos desafios socioambientais encontrados na construção do desenvolvimento sustentável.

\section{Agradecimentos}

Esta pesquisa contou com o apoio da Colônia de Pescadores de Manoel Urbano Z5, Associação de Pescadores de Pirarucu de Manoel Urbano e SEAPROF. Aos técnicos Ana Francisca D. de Negreiro, Thaline F. Brito, Cristiana G. Simões, Carlos Leopoldo L. de Oliveira, Marcelo Crossa, Juan Negret e Evandro Câmara; e pescadores Francisco Antônio, José Soares, Antônio Lulu, José Amaro de Souza, José dos Santos Pessoa, Antônio Amaro Soares e Raimundo Gomes dos Santos pela valiosa contribuição.

\section{Referências}

AGRAWAL, A. 1999. Greener pastures: Politics, markets, and Community among a migrant pastoral people. Durham: Duke University Press. 219p.

ALBERT, J.S., R.E. Reis. Editors. 2011. Historical biogeography of Neotropical freshwater fishes. University of California Press. 424p.

ALMEIDA, O., K. LORENZEN, e D.G. MCGRATH. 2009. Fishing agreements in the lower Amazon: for gain and restraint. Fisheries Management and Ecolog, 16: 61-67. APPADURAI, A. 1986. The social life of things: commodities in cultural perspective. Cambridge: Cambridge University Press. 339p.

AYRES, D.L. 1994. A implantação de uma unidade de conservação em área de várzea: a ex-periência de Mamirauá, in Amazônia e a crise da modernização. Editado por M.A. D’Incao, e I.M. Silveira, pp. 403-409. Belém: Museu Paraense Emílio Goeldi.

AYRES, M., M. Ayres Junior, D.L. Ayres, e A.L. Santos. 2007. BioEstat: aplicações estatísticas nas áreas das ciências bio-médicas. Belém: Museu Paraense Emílio Goeldi/CNPq. p. 380. 
BEGOSSI, A. 2006. The ethnoecology of Caiçara metapopulations (Atlantic Forest, Brazil): Ecological concepts and questions. Journal of Ethnobiology and Ethnomedicine 2(1): 40. Disponível em http://www.ethnobiomed.com/content/2/1/40

BERNARD, H.R., e G.W. Ryan. 2010. Analysing qualitative data: systematic approaches. California: SAGE Publication. 451p.

BERKES, F. 2008. Sacred ecology. New York: Routledge. 392p.

CASTELLO, L. (2004). A method to count Pirarucu Arapaima gigas: fishers, assessment, and management. North American Journal of Fisheries Management, 24: 379-389.

CASTELLO, L., M. PINEDO-VASQUEZ, e P. VIANA. 2011. Participatory conservation and local knowledge in the Amazon várzea: the pirarucu management scheme in Mamirauá, in The Amazon Varzea: The Decade Past and The Decade Ahead. New York: SpringerVerlag, pp. 261-276.

CASTRO, F., e D.G. MCGRATH. Moving toward sustainability in the local management of floodplain lake fisheries in the Brazilian Amazon. Human Organization 62(2): 2003, p. 123-133.

COSTA-NETO, E.M., C.V. Dias, e M.N.O. Melo. 2002. Conhecimento ictiológico tradicional dos pescadores da cidade de Barra, região do médio São Francisco, estado da Bahia, Brasil. Acta Scientiarum 24(2): 561-572.

DIEGUES, A.C. 1999. A sócio-antropologia das comunidades de pescadores marítimos no Brasil. Etnográfica 3(2): 361-375.

GEERTZ, C. 1989. A interpretação das culturas. LTC Editora: Rio de Janeiro. 213p.

INGOLD, T. 2000. The perception of the environment: essays on livelihood, dwelling and skill. London: Routledge. 465p.

INGOLD, T. 2010. Da transmissão de representações à educação da atenção. Educação 33(1): 6-25.

INGOLD, T. 2011. Being alive: Essays on movement, knowledge and descrioption. London: Routledge. 288p.

KOTHARI, A. 2006. Community conserved areas: towards ecological and livelihood security. Parks 16(1): 3-13.

LEME, A. S., e A. BEGOSSI. 2004. Uso de recursos por ribeirinhos no médio rio Negro, in Ecologia de pescadores da Mata Atlântica e da Amazônia. Editado por A. Begossi, A. Leme, A., C. S. Seixas, F. Castro, J. Pezzuti, N. Hanazaki, N. Peroni, e R.A.M. Silvano, pp. 89-148. São Paulo: Hucitec.

LINCOLN, Y. S., e E.G. Guba. 1985. Naturalistic Inquiry. California: Sage. 416p.

LORENZEN, K, O. ALMEIDA, R. Arthur, C.J. GARAWAY, e S.N. KHOA. 2006. Aggregated yield and fishing effort in multispecies fisheries: an empirical analysis. Canadian Journal of Fisheries and Aquatic Sciences 63(6): 1334-1343.

MARQUES, J.G. W.2001. Pescando pescadores: Ciência e etnociência em uma perspectiva ecológica. $2^{\mathrm{a}}$ ed. Núcleo de Apoio à Pesquisa sobre Populações Humanas e Áreas Húmidas Brasileiras. São Paulo: USP. 258p. 
MCGRATH, D.G., A. Cardoso, O. Almeida, e J. Pezzuti. 2008. Constructing a policy and institutional framework for an ecosystem-based approach to managing the Lower Amazon floodplain. Environment, Development and Sustainability 10: 677-695.

MCGRATH, D.G., L. Castello, O. Almeida, e G.M.B. Estupinan. 2015. Market formalization, governance, and the integration of community fisheries in the Brazilian Amazon. Society \& Natural Resources 28(5): 513-529.

MOURÃO, J. S., e N. NORDI. 2003. Etnoictiologia de pescadores artesanais do estuário do rio Mamanguape, Paraíba, Brasil. Boletim Instituto de Pesca 29(1): 9- 17.

OVIEDO, A. F. P., M. BURSZTYN, e J. DRUMMOND. 2015. Now under new administration: fishing agreements in the Brazilian Amazon floodplains. Ambiente \& Sociedade 18(4): 113-132.

OVIEDO, A. F. P., e M. BURSZTYN. 2016. The fortune of the commons: participatory evaluation of small-scale fisheries in the Brazilian Amazon. Environmental Management $57: 1009-1023$.

OVIEDO, A. F. P., e M. CROSSA. 2011. Manejo do pirarucu - sustentabilidade nos lagos do Acre. ISBN 978-85-86440-74-8. Brasília: WWF-Brasil. 67p.

PRINCE, J. 2003. The barefoot ecologist goes fishing. Fish and Fisheries 4: 359-371.

RAFFESTIN, C. 1993. Por uma geografia do poder. São Paulo: Ática. 33p.

ROZZI, R., F. MASSARDO, C.B. ANDERSON, K. HEIDINGER, e J.A SILANDER JR. 2006. Ten principles for biocultural conservation at the southern tip of the Americas: the approach of the Omora Ethnobotanical Park. Ecology and Society 11(1): 43.

RUDDLE, K. 1993. The transmission of traditional ecological knowledge, in Traditional ecological knowledge: concepts and cases. Editado por J.T. Inglis, pp. 17-31. Ottawa: International Development Research Centre.

RUFFINO, M. L. 2008. Sistema integrado de estatística pesqueira para a Amazônia. Pan-American Journal of Aquatic Sciences 3(3): 193-204.

SANTOS, M. 1996. Metamorfose do espaço habitado. 4. ed. São Paulo: Hucitec.

SANTOS FILHO, L.C. 2005. Avaliacão da explotação pesqueira e dinâmica populacional de matrinxã Brycon amazonicus (Günther, 1869) (Pisces: Characiformes) explotado pela frota pesqueira que desembarca em Manaus = Amazonas, Brasil. Dissertação de Mestrado. Instituto Nacional de Pesquisas da Amazônia. Universidade Federal do Amazonas-UFAM. Programa Integrado - PG-BTRN/CPG-BADPI). 120p.

SCHWARTZ, M.S., e C.G. SCHWARTZ. 1955. Problems in participant observation. American Journal of Sociology 60(4): 343-353.

SILVANO, R.A.M. 2004. Pesca artesanal e etnoictiologia, in Ecologia de pescadores da Mata Atlântica e da Amazônia. Editado por A. Begossi, pp. 185-220. São Paulo: Hucitec.

SILVANO, R.A.M., e A. BEGOSSI. 2005. Local knowledge on a cosmopolitan fish ethnoecology of Pomatomus saltatrix (Pomotomidae) in Brazil and Australia. Fisheries Research 71: 43-59.

VERBI SOFTWARE. 2017. MAXQDA 12 Reference Manual. Berlin: Consult. Sozialfors- 
chung. p. 440.

VIERTLER, R. B. 2002. Métodos antropológicos como ferramenta para estudos em etnobiologia e etnoecologia, in Métodos de coleta e análise de dados em etnobiologia, etnoecologia e disciplinas correlatas. Editado por M.C. Amoroso, L.C. Ming, e S.M.P. Silva, pp. 11-30. Rio Claro: Ed. Unesp.

VOGT, N., M. PINEDO-VASQUEZ, E.S. BRONDIZIO, F.G. Rabelo, K. Fernandes, O. Almeida, S. Riveiro, P.J. Deadman, e Y. Dou. 2016. Local ecological knowledge and incremental adaptation to changing flood patterns in the Amazon delta. Sustainability Science 1-13.

WELCOMME, R.L. 1999. A review of a model for qualitative evaluation of exploitation levels in multi-species fisheries. Fisheries Management and Ecology 6: 1-19. 